\title{
The Pore Structure of Phosphoaluminate Cement
}

\author{
Weilun Wang ${ }^{1}$, Peng Liu ${ }^{2}$, Ming Zhang ${ }^{2}$, Jiashan $\mathrm{Hu}^{1}$, Feng Xing ${ }^{1}$ \\ ${ }^{1}$ Guangdong Provincial Key Laboratory of Durability for Marine Civil Engineering, Shenzhen University, Shenzhen, China; ${ }^{2}$ School \\ of Civil Engineering and Architecture, Central South University, Changsha, China. \\ Email: wang_weilun@hotmail.com
}

Received March 21 $1^{\text {st }}, 2012$; revised April 18 ${ }^{\text {th }}, 2012$; accepted May $1^{\text {st }}, 2012$

\begin{abstract}
The effects of curing time and water-to-cement ratio (W/C) on the pore structure of phosphoaluminate cement (PAC) paste are here presented. Based on the adsorption and condensation theory, the adsorption isotherm of hardened paste was tested using the Brunauer-Emmett-Teller (BET) nitrogen adsorption method. The phase composition and morphology of hydration products cured at different times were analyzed using X-ray diffraction (XRD), and a hydration heat test instrument (HHT) was employed to determine the heat of hydration. The effects of curing time and W/C on the pore structure of PAC are significant. The adsorption isotherm is fitted to the second category based on the Brunauer-Deming-Deming-Teller (BDDT) classification system. Adsorption volume was found to increase with W/C and then decrease with age. The hysteresis loop of PAC is fitted to the $\mathrm{H} 3$ type based on International Union of Pure and Applied Chemistry (IUPAC) guidelines, and the adsorption volume and area enclosed by the hysteresis loop were found to increase with W/C and then decrease with age. BET surface and saturated adsorbed volume of PAC both increase with $\mathrm{W} / \mathrm{C}$ and decrease with curing time, which is attributable to the greater hydration that produces and changes the characteristics of the pore structure.
\end{abstract}

Keywords: Phosphoaluminate Cement; Pore Structure; Adsorption; Curing Time

\section{Introduction}

Hardened cement paste is usually considered a multiphase composite material, and its porosity could be considered one of its most important composing parameters. In cement, porosity is the result of air mixed into the cement, vaporization of free water, and generation of hydrates [1-3]. According to their sizes, pores can be classified as macropores (radii $\geq 50 \mathrm{~nm}$ ), mesopores (radii 2 $50 \mathrm{~nm}$ ), and micropores (pore radii $\leq 2 \mathrm{~nm}$ ), and each kind is characterized with a distinctive type of adsorption isotherms. Since the aperture of the micropore is only a few molecules in diameter. The potential fields of the contiguous pore walls are overlapped with one another $[4,5]$. This intensifies the interaction between the adsorbent and the gas molecule, resulting in a dramatic increase in adsorption quantity (a) even at low relative pressures $\left(P / P_{0}\right)$. The adsorption soon levels off because saturation pressure is achieved. Thus, the corresponding adsorption isotherms of microporous materials have a steep, positive initial slope and followed by a long horizontal line over a broad range of relative pressures. On the other hand, the adsorption isotherms of materials with mesopores are characterized by hysteresis loops because only a portion of the adsorbed gas is released when undergoing desorption process. Finally, the adsorption of gas onto macroporous materials continues with pressures until the relative pressure approaches 1.0 [6]. The pore structure of the cement concrete has a direct effect on its anti-proliferative, frost-resistant, and anticorrosive proerties [7-12]. However, since curing time and $\mathrm{W} / \mathrm{C}$ also have significant effects on the pore structure of the hardened cement paste. Therefore, it is extremely important to understand these internal relationships for the durability of cement concrete [13,14].

Phosphoaluminate cement (PAC) is an anionic specialty cement with the $[\mathrm{P}-\mathrm{O}]$ and $[\mathrm{Al}-\mathrm{O}]$ present as the primary components [15]. The main hydration products of PAC are calcium phosphorus aluminate hydrate, calcium phosphate hydrate, calcium aluminate hydrate, and gels. There is no calcium hydroxide or ettringite formed during the process of the hydration. Portland cements (PC) are the most common cementitious materials used in the making of concrete structures. The main hydration products of $\mathrm{PC}$ are calcium hydrate $(\mathrm{CH})$, calcium silicate hydrate (C-S-H), and so on. $\mathrm{CH}$ easily reacts with sulfate and produces expansile products which can destroy the structures. So its applications are limited. On the other hand, Phospho aluminate cement (PAC), as a new cementitious material, has many special properties compared to PC. 
The embedded properties of PAC could satisfy the requirements of concrete durability in specific environments. Based on the adsorption agglomeration theory and the adsorption characteristics of different kinds of pores at liquid nitrogen temperature the influential regularity of the pore structure of the hardened PAC paste is investigated. In the present paper, adsorption isotherms and hysteresis loops were collected, the Brunauer-EmmettTeller (BET) surface areas were derived, the stages of hydration were examined and the mechanism of early phase hydration was discussed.

\section{Principle}

\subsection{Types of Adsorption Isotherms}

The interactive relationships among the superficial properties, pore structure features of adsorption, and adsorption itself can be reflected through the adsorption isotherm. The Brunauer-Deming-Deming-Teller (BDDT) classification methodology categorizes the gas adsorption isotherm into five fundamental types, as illustrated in Figure 1 [16].

The first type of the adsorption isotherm is called single-molecule adsorption, and it is characterized by continuous increases in the adsorption volume till the relative pressure surpasses a certain value. This also occurs when the multi-layer adsorption fills up the micropore. Single-molecule adsorption is suitable for depicting a situation in which the adsorption temperature is higher than the critical temperature of the adsorbate. The second type exhibits a slow increase in the convex curve in the first half $(\mathrm{AB})$ and a sharp increase in the second half of the isotherm (BC) because of multilayered adsorption, capillary filling, and capillary condensation. Under these circumstances, no adsorption saturation point exists on the curve. This fits situations in which the adsorption temperature is lower than the critical temperature of the adsorbate. This category has what is called an anti-Sshaped adsorption isotherm. The third type of adsorption isotherm exhibits a gradual increase of the adsorption volume with the relative pressure. The surface area of the adsorption agent has the same pore allocation as the second type, and the difference only lies in the interaction between the adsorbent and the adsorbate. In the fourth type of adsorption isotherm, both the adsorption volume and the adsorption rate increase with relative pressure.
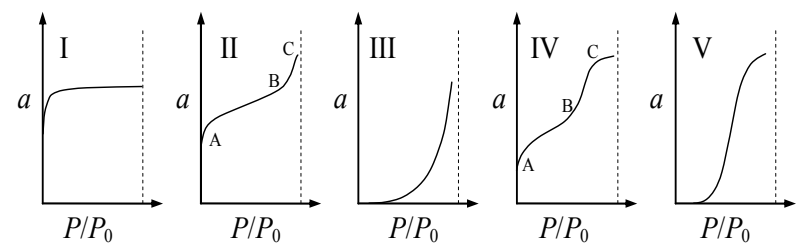

Figure 1. Categories of adsorption isotherms (BDDT).
The first half of the isotherm (AB) appears to be similar to the type II isotherm. However, when the relative pressure exceeds a certain value, the adsorption isotherm (BC) tends to level off. This is closely related to the pore radii of the larger pores in the adsorbent. The S-shaped adsorption isotherm is defined as the fifth type of adsorption isotherm. This type isotherm (type V) in low relative pressure indicates that the interactions between adsorbate and adsorbent are weak, the isotherm in the middle and high relative pressure shows the number of pore in the system is limited, and the number of adsorption layers is also finite.

\subsection{Adsorption Hysteresis Loops and Their Classification}

The behavior of the nitrogen adsorption can be described according to the adsorption condensation theory. When relative pressures $P / P_{0}$ are lower than 0.05 , nitrogen is adsorbed in the form of single molecules. With an increase in relative pressure, multi-layered adsorption and subsequent capillary condensation occur in some small micropores which are larger than the pore of monomolecular adsorption, accompanied with increases in the amount of adsorption. The corresponding Kelvin radius can be calculated using Equation (1) [17]. When the relative pressure achieves a particular high value, capillary condensation approaches the largest pore size, and the processes of adsorption and condensation are terminated. With a decrease in relative pressure, the nitrogen absorbed starts to desorpt, and the adsorption layers weaken. When the relative pressure decreases to a certain point, capillary evaporation occurs, and the condensed nitrogen starts to desorpt. When the shapes of the capillary pores are similar, the relative pressure of evaporation and condensation are equal, and the adsorption and desorption branches of the adsorption isotherm coincide with each other. The relative pressure can be calculated using Equation (2).

On the other hand, if the two relative pressures are different, the evaporation relative pressure can be calculated using Equation (3). That is caused by the micro structure of pore, such as inkbottle pore. In these cases, the adsorption and desorption branches of the adsorption isotherms do not coincide, resulting in the formation of the hysteresis loops. The shapes of the hysteresis loops provide information of pore structures. Therefore, the pore structures of various materials can be indirectly analyzed by investigating the hysteresis loops.

$$
\begin{aligned}
& r_{k}=-\frac{2 \gamma V_{m} \cos \varphi}{R T \ln x} . \\
& x_{c}=\exp \left(-\frac{\varphi V_{m}}{R T r_{k}}\right) .
\end{aligned}
$$




$$
x_{v}=\exp \left(-\frac{2 \varphi V_{m}}{R T r_{k}}\right) .
$$

here $\varphi$ is the contact angle $\left(0^{\circ}\right) ; x$ is the relative pressure $\left(x=P / P_{0}\right) ; V_{m}$ is the single molecule saturation adsorption volume, $34.65 \times 10^{-4} \mathrm{~m}^{3} ; \gamma$ is the surface tension of the liquid, $8.85 \times 10^{-3} \mathrm{~N} / \mathrm{m} ; R$ is the ideal air constant, $8.314 \mathrm{~J} / \mathrm{K} \cdot \mathrm{mol} ; T$ is the temperature of the liquid nitrogen, $77.35 \mathrm{~K} ; x_{c}$ and $x_{v}$ are the relative pressures for the capillary condensation and evaporation under a specific condition; and $r_{k}$ is the Kelvin radius of the pore, $\times 10^{-10} \mathrm{~m}$.

The hysteresis loops can be divided into four categories based on the IUPAC guideline, as shown in Figure 2. $\mathrm{H} 1$ and $\mathrm{H} 4$ represent two extreme cases, and $\mathrm{H} 2$ and $\mathrm{H} 3$ are the intermediate situations.

The adsorption and desorption branches of $\mathrm{H} 1$ are almost vertical and nearly parallel over an appreciable range of gas uptake. The adsorption and desorption branches of $\mathrm{H} 4$ are almost horizontal and nearly parallel over a wide range of relative pressure. The shapes of hysteresis loops are associated with specific pore structures.

For example, porous materials which consist of wellaligned, spheres and briquettes can produce an H1 type loop line, and materials of this type tend to have relatively narrow distributions of pore size. For the $\mathrm{H} 2$ type loops, the hysteresis loop is wide, and the desorption curve is more precipitous than the adsorption curve. This situation usually occurs when the distributions of pore size radii are wide. The presence of slit-shaped pores and/or panel-shaped particles generates the $\mathrm{H} 3$ and $\mathrm{H} 4$ curves. However, the exhibition of H4 loops indicates the existence of the micropore.

\subsection{Normalized Surface Areas of the Voids}

Based on the simple multi-layered adsorption model, the Brunauer-Emmett-Teller (BET) method has an acceptable degree of accuracy because of its simplicity and good duplicity. BET has become one of the standard methods of determining normalized surface areas of multi-pored substances [11]. The classical BET equation is shown in Equation (4).

$$
\frac{x}{(1-x) V}=\frac{1}{\mathrm{C} V_{m}}+\frac{\mathrm{C}-1}{\mathrm{C} V_{m}}
$$

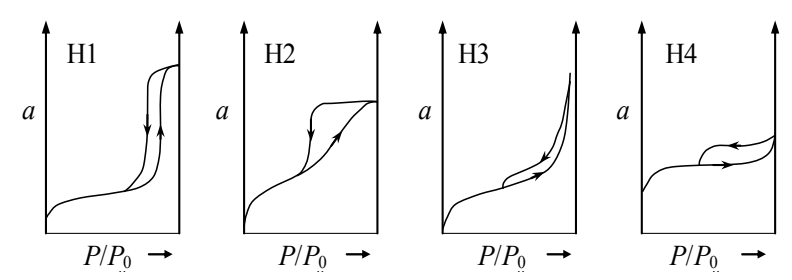

Figure 2. Categories of gas adsorption loops (IUPAC).

$$
S_{t}=4.36 V_{m} .
$$

here $V$ is the corresponding adsorption volume at the relative sub-pressure $x ; V_{m}$ is the saturated adsorption volume; and $\mathrm{C}$ is the constant and is related to the heat of adsorption in the first adsorbed layer. When $x$ is any value between 0.05 and 0.35 , the curve of $x /(1-x) V$ vs. $x$ is a straight line. Therefore, $V_{m}$ and $\mathrm{C}$ can be calculated based on the slope and the intercept of the curve. When the molecule of the cross-sectional area is given as 0.16 $\mathrm{nm}^{2}$, the surface area of the sample can be calculated using Equation (5).

\section{Experimental Procedures}

\subsection{Raw Materials}

The primary material used in the experiment is PAC, which is mixed with laboratory-grade fire retardant, industrial-grade borax $(0.8 \%$ of the cement quantity), and tap water in accordance with Chinese standard JGJ631989 Concrete Max Water. The physical properties of PAC are listed in Table 1.

\subsection{Methodology and Equipments}

Samples were made in $30 \times 30 \times 30 \mathrm{~mm}$ molds and divided into groups of 24 pieces each based on the different $\mathrm{W} / \mathrm{C}$ values. They were placed in an environmental chamber with temperature kept at $20^{\circ} \mathrm{C} \pm 1{ }^{\circ} \mathrm{C}$ and the relative humidity of $90 \% \pm 4 \%$ for $6 \mathrm{~h}$ for curing. They were then demolded, and curing was continued until they reached the desired time periods, at which point the hydration process was terminated with alcohol. The samples were then vacuum-dried for XRD, SEM, and BET analyses. Then, a $10.00 \mathrm{~g}$ piece of cement was weighed and placed in a specialized tube. The tube with the injecttor contained $4.60 \mathrm{~g}$ water was placed inside the hydration thermal tester and carried out an experiment upon HHT analysis in accordance with the manufacturer's instructions.

The equipments primarily included DX-2500 type X-ray diffractometry produced by Fangyuan Co. Ltd. in Dandong, China for XRD measurement, Toni 7338 type Hydration heat tester produced by Toni Technik GmBH in Germany for HHT graphs, S-2500 type scanning electron microscope produced by Hitachi in Japan for SEM examination, and TriStar 3000 type surface area and porosity analyzer produced by Micromeritics company in

Table 1. Physical properties of cement.

\begin{tabular}{ccccc}
\hline Item & $\begin{array}{c}\text { Average pore } \\
\text { diameter }(\mu \mathrm{m})\end{array}$ & $\begin{array}{c}\text { Initial setting } \\
\text { time (min) }\end{array}$ & $\begin{array}{c}\text { Final setting } \\
\text { time (min) }\end{array}$ & $\begin{array}{c}\text { Water requirement } \\
\text { for standard } \\
\text { consistency }(\%)\end{array}$ \\
\hline PAC & 32.8 & 118 & 142 & 26 \\
\hline
\end{tabular}


America for BET surface area and porosity measurements.

\section{Results and Discussion}

\subsection{Effects of Curing Time and $\mathrm{W} / \mathrm{C}$ on the PAC Adsorption Isotherm}

Figure 3 shows adsorption isotherms of various PAC paste samples. These samples were hardened with various curing time periods and these samples consist of various $\mathrm{W} / \mathrm{C}$ values. The corresponding XRD curves for aged samples with a constant $\mathrm{W} / \mathrm{C}$ of 0.46 are shown in Figure 4, so that the composition changes as a function of the curing time can be examined. The thermal curves including heat generation and rate of the heat generation due to the hydration reactions of PAC samples tested according to the Section 3.2 are shown in Figure 5.

As in Figure 3, the hardened PAC paste samples exhibit BDDT Type II adsorption isotherm: The nitrogen gas uptake during the first half of the isotherm slowly increased with absence of the initial peak, this indicates that the adsorption mechanism had been transmitted from the single molecule adsorption to the multi-layered ad-
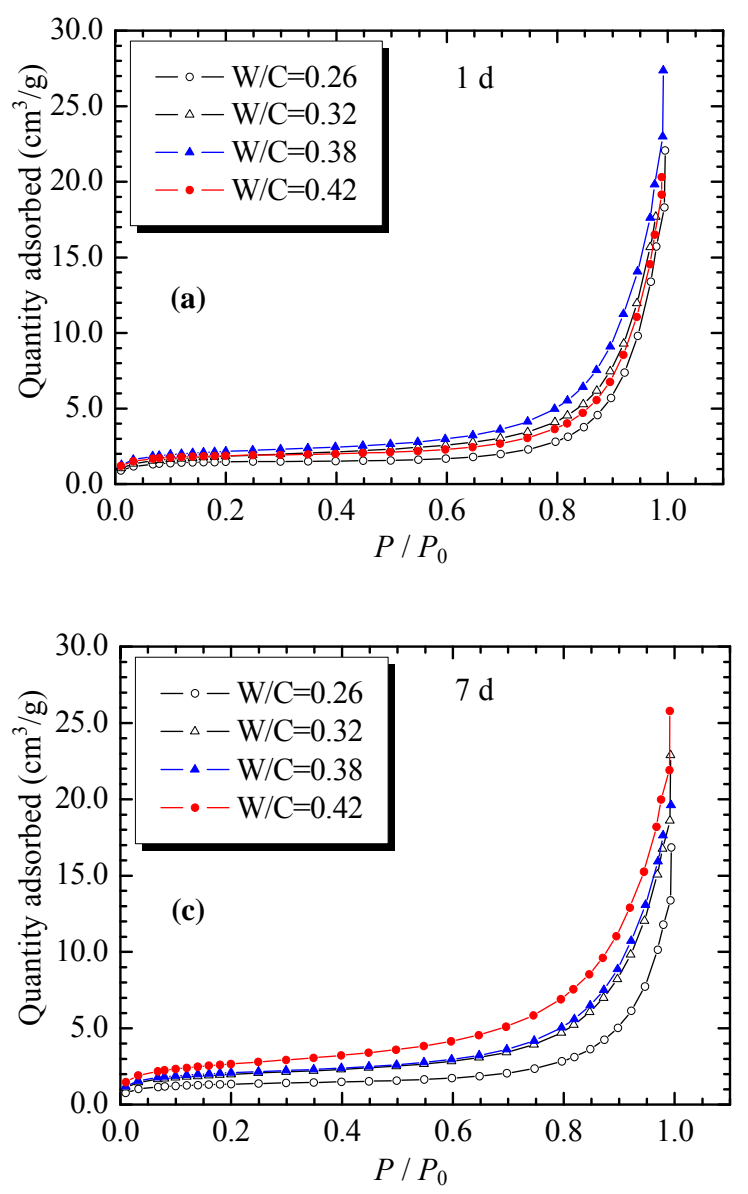

sorption in the hardened paste. However, the gas uptake sharply increased during the final half of the isotherm, indicating that capillary condensation occurred. The curve shows the pores of PAC is the continuous pore system from the molecular level up to the relatively unlimited pore sizes. In other words, the distribution of pore size is wide from nanometer to millimeter level. The quantity of nitrogen adsorption increases with the increasing $\mathrm{W} / \mathrm{C}$, resulting in an increase in the porosity of the hardened paste.

When the relative pressure is low $\left(P / P_{0} \leq 0.6\right)$, the effect of $\mathrm{W} / \mathrm{C}$ on the characteristics of the adsorption isotherms is insignificant, and the pore type is not obvious. The only difference lies in the quantity of gas uptake. When the relative pressure is high $\left(0.6<P / P_{0} \leq 1.0\right)$, the difference in the gas uptake became more pronounced as $\mathrm{W} / \mathrm{C}$ increases, suggesting that the effect of $\mathrm{W} / \mathrm{C}$ on the adsorption isotherm is distinctive. This attribute to pores becoming filled so that the intensity is increased. In addition, certain minerals that PAC contains can react with water via special hydration mechanisms, thus forming three-dimensional micro-structures at early stage. This occurrence can be confirmed by substantial composition
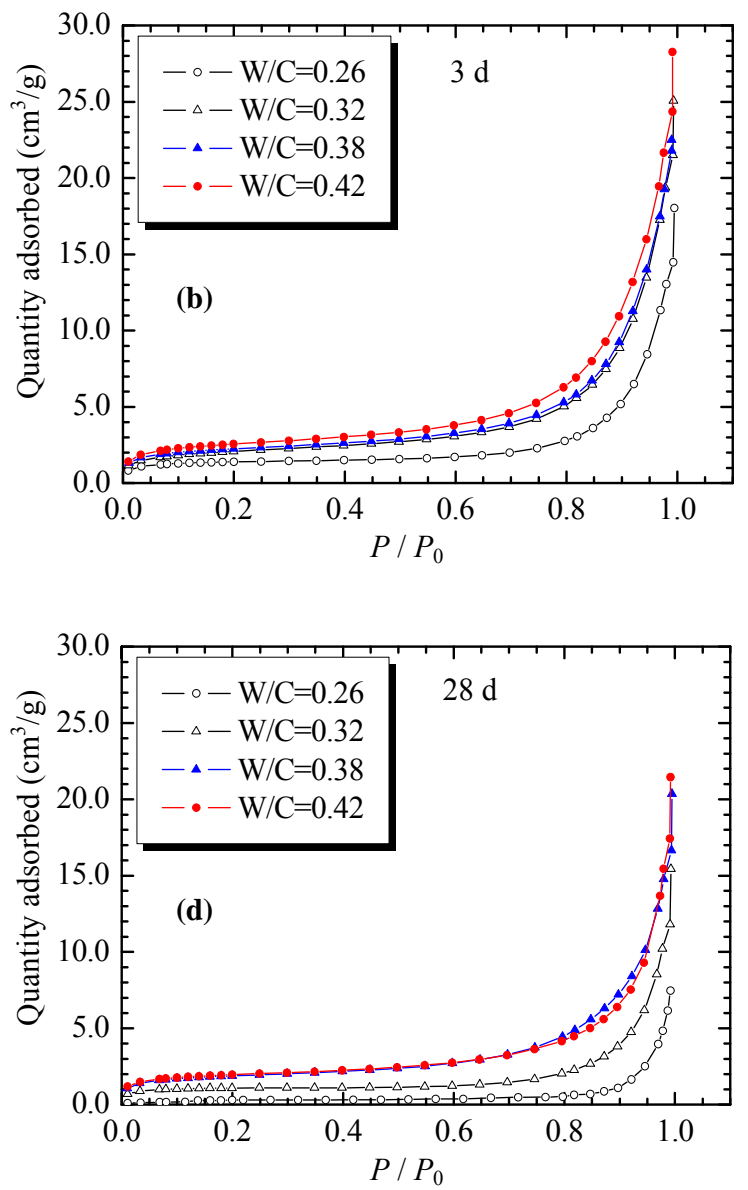

Figure 3. Adsorption isotherm of PAC paste with different $\mathrm{W} / \mathrm{C}$ and curing times. 


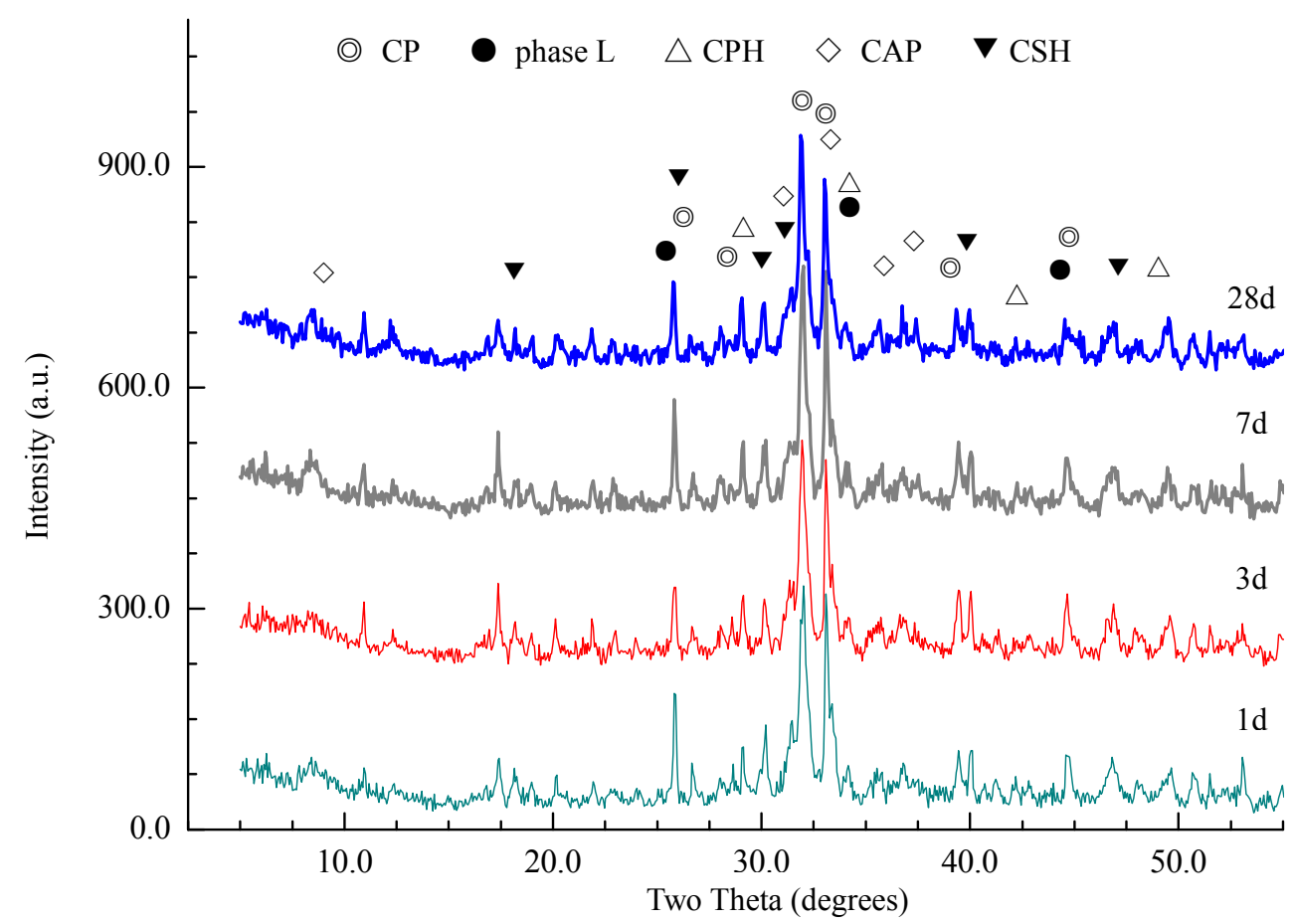

Figure 4. X-ray diffraction of PAC paste.

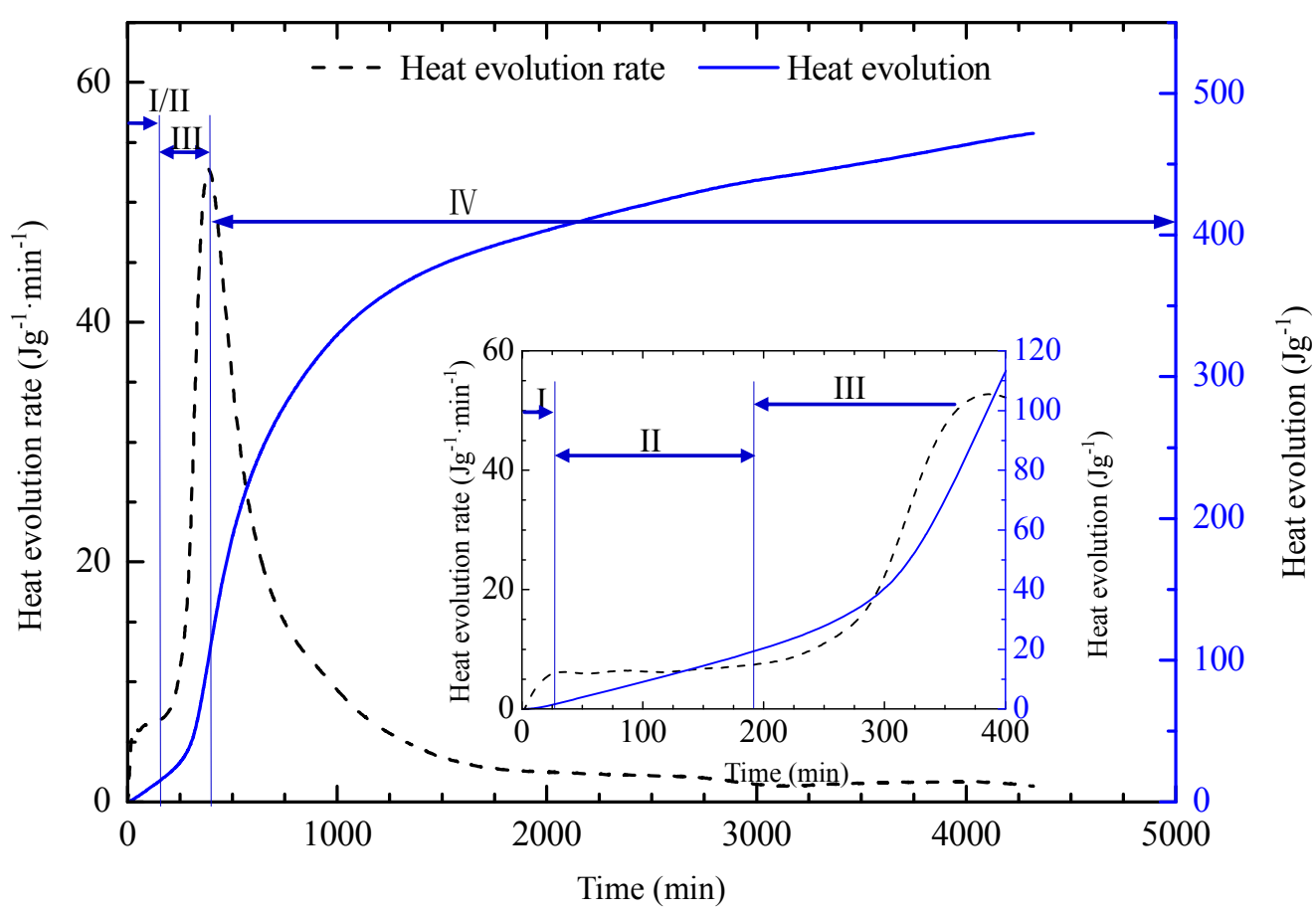

Figure 5. Curve of hydration heat release of PAC (I: Dissolution; II: Induction; III: Acceleration; IV: Deceleration).

analysis of samples which all have same W/C of 0.46, but undergone various curing time periods. Since hydration occurs during curing, samples with longer curing periods should undergo more complete hydration The hydration products of PAC shown in Figure 4, include calcium phosphate-aluminate hydrates (CAP), phase L, calcium phosphate hydrate (CP) microcrystals, calcium silicate hydrate (CSH), and hydroxyapatite (CPH) $[15,18$, 19]. These substances can connect with one another to improve the intensity of the system, and the resultant product can be used to fill the pores of the hardened paste and reduce porosity. Some differences, such as the 
strength and the width of diffraction peaks, were observed when comparing the composition graphs of various PAC paste samples, hardened with $1 \mathrm{~d}$ and $3 \mathrm{~d}$ can be interpreted from Figure 4. For example, the diffraction peaks' strength $\left(2 \theta\right.$ is $\left.11^{\circ}, 17.3^{\circ}, 40^{\circ}, 44.6^{\circ}, 46.9^{\circ}\right)$ of the sample cured for $3 \mathrm{~d}$ increase, which indicates that the crystal form of hydrates become more integrated and the quantity become more; the values $\left(2 \theta\right.$ is $25.8^{\circ}, 30.2^{\circ}$ ) decrease, which maybe due to the hydrates transforming into others. However, the difference between 3, 7, and 28 $\mathrm{d}$ is insignificant, suggesting that the PAC hydration reaction primarily occurs during the early stage.

The micro-structure also forms during the early stages, as illustrated in Figure 5. The hydration thermal curve of a cement sample with $\mathrm{W} / \mathrm{C}$ of 0.46 shows a rapid initial hydration with significant heat generation. However, this hydration process subsequently slows down and less heat was generated as time increases. Therefore, the corresponding rate of hydration exists a sharp peak. A close look of both curves reveals four distinctive phases at the early stage of hydration, including periods of dissolution, induction, acceleration, and deceleration $[11,12]$. When time approaches to $3 \mathrm{~d}$, the heat generated increased little, whereas the thermal rate tends to approach zero, suggesting that the PAC pore structure is formed during the early stages. These viewpoints could be proven through micro-structure analysis.

Figure 6 shows the compressive strength of PAC paste (W/C is 0.26 ) that has been cured with various time periods. Figure 7 shows the SEM graph of the corresponding PAC paste cured for 3 days.

According to Figure 6, it can be seen that the compressive strength of PAC increases with curing time. This curve reflects a rapid initial increase at shorter curing time periods, and the increase slows down as curing time prolongs. The compressive strength of PAC cured for $3 \mathrm{~d}$ could be $85 \%$ of its final strength. This shows that the compact micro structure of PAC paste has already been

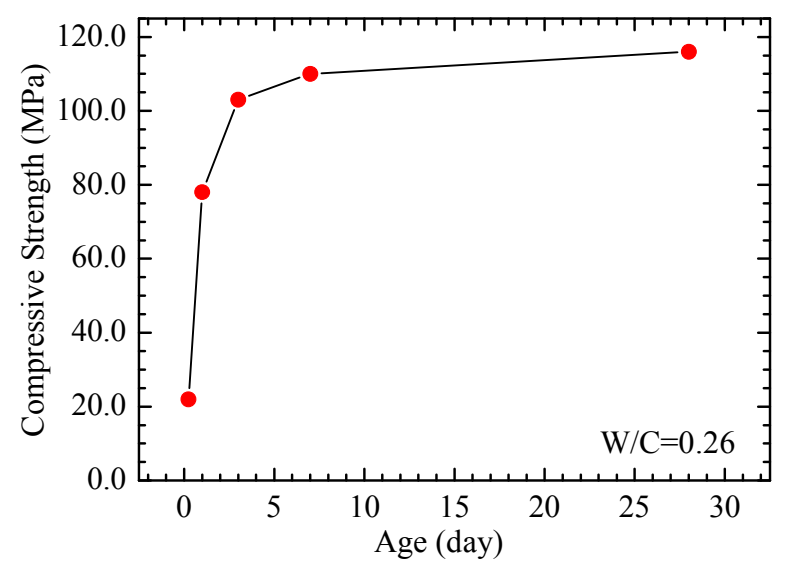

Figure 6. Compressive strength of PAC paste.

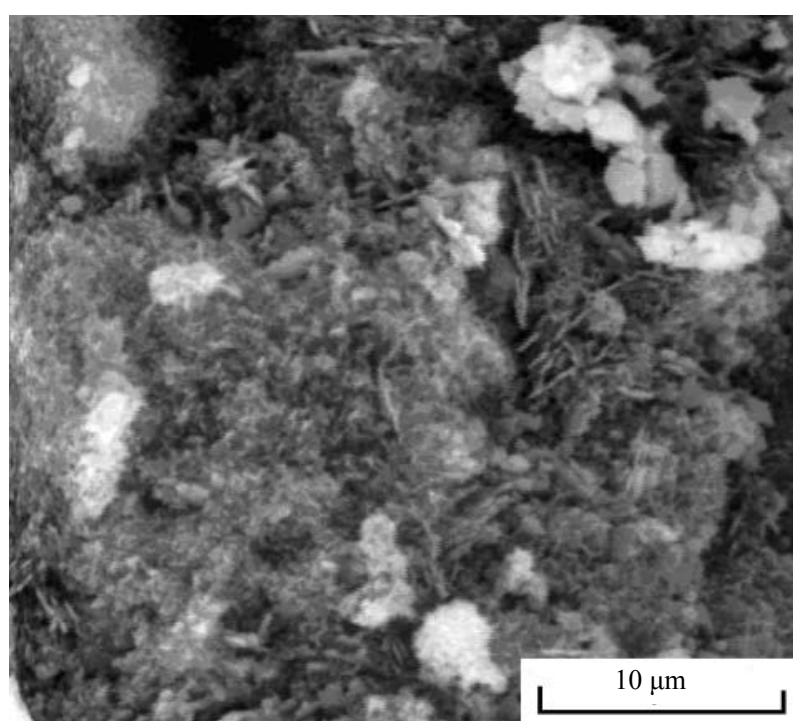

Figure 7. SEM of PAC paste cured for $3 \mathrm{~d}$.

created. Figure 7 could be used to prove this, the microstructure of the hardened PAC paste appears to have been intensified, showing fewer pores and less porosity. The hydration of the mineral ingredients and the transforming them into cotton-shaped gels result in relatively low porosity and small pore sizes. This change in pore structure and microstructure of PAC is important because it affects the penetrating properties of the cement. Regarding the analyses in Figures 4-7, the gel-forming minerals peculiar to PAC determine the features of rapid hydration, whereas the features of the hydration products determine the microstructure, which, as a more important parameter than the pore structure, in turn determines adsorptiondesorption behaviors.

\subsection{Effects of Curing Time and $W / C$ on the Adsorption Hysteresis Loop}

The hysteresis loops of the hardened PAC pastes with various $\mathrm{W} / \mathrm{C}$ values and various curing time periods are illustrated in Figure 8. Based on Figure 8, these curves conforms to the IUPAC type H3 loops, which suggests that the internal porosity of the hardened paste primarily is slit-shaped and panel-shaped. This can be understood when the pore size is considered two-dimensional and three-dimensional. These features are beneficial because they lead to reduction in liquid diffusion and reduction of proliferation volumes, improving the anti-proliferative property of the system.

Both the nitrogen uptake and the area enclosed by the hysteresis loops decrease as curing time increases and both increase as $\mathrm{W} / \mathrm{C}$ increases. The shape change of the hysteresis loops reflects the improvement in the pore structure, which is attributable to the continuous filling, specifying, and intercepting of the pores due to gel formation 

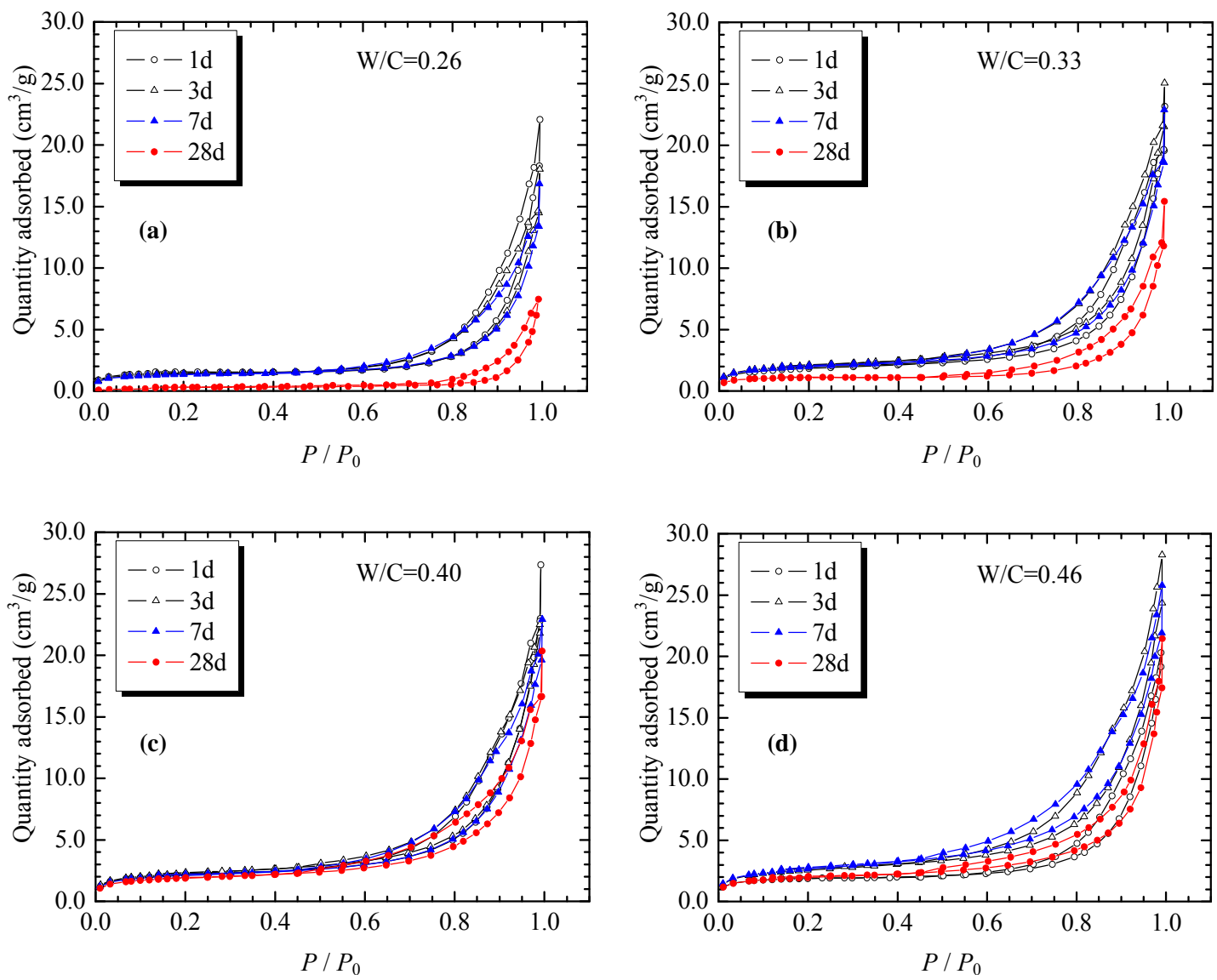

Figure 8. Hysteresis loops of PAC paste with various $W / C$ and curing times.

during hydration. Samples with a larger $\mathrm{W} / \mathrm{C}$ result in larger pores and increased the pore formation during the later phase of the hydration (e.g. 28 d). This is attributeable to evaporation and hydration. Furthermore, the adsorption isotherms of the paste in the later phase of the hydration are obviously different from those in the early phase ( $1 \mathrm{~d}$ and $3 \mathrm{~d}$ ), which is attributable to the continuous improvement of the pore structure.

\subsection{Effects of Curing Time and W/C on Pore Structure of PAC Paste}

Figure 9 illustrates the BET surface area as a function of curing time and W/C. Figure 10 shows the relation between saturated adsorption volume and curing time.

As shown in Figures 9 and 10, the BET surface area of the PAC paste and the saturation adsorb volume vary with curing time. Quantity changes less during the early stages $(1 \mathrm{~d}-3 \mathrm{~d})$ than during the later phase $(28 \mathrm{~d})$. With the increase in $\mathrm{W} / \mathrm{C}$, the change in quantity increases. A reduction in $\mathrm{W} / \mathrm{C}$ results in a more obvious variance between the early and later stages. As curing time increases, the generated hydration products change the distributions of pore size. These newly formed hydrates also fill and intercept the pores, and reduces the overall porosity of the system so that both the surface area and the saturation nitrogen adsorption volume are decreased. On the other hand, with an increase in $\mathrm{W} / \mathrm{C}$, the more redundant water which doesn't react with cementitious minerals exists in the hardened paste, the more porosity will be generated. Therefore, enlarging the surface area and increasing the amount of saturated nitrogen adsorbed will be appearance. The surface saturated adsorption quantity of the medium period hydration can be said to decrease less as curing time goes on. This may explain the cross-over of curves. Thereby increasing the surface area and the amount of saturated material adsorbed. This occurrence might be attributable to the continuous generation of hydration product filling and altering the large pores in such a way that they are transformed from super large pores to micropores or mesopores. However, the decrease in the number of micropores is smaller than the number of large pores transformed into other pores. The as-tested absolute micropore quantity becomes increased because of the limited testing range of the machine.

\section{Conclusions}

Based on the current study, the following conclusions can be drawn: 


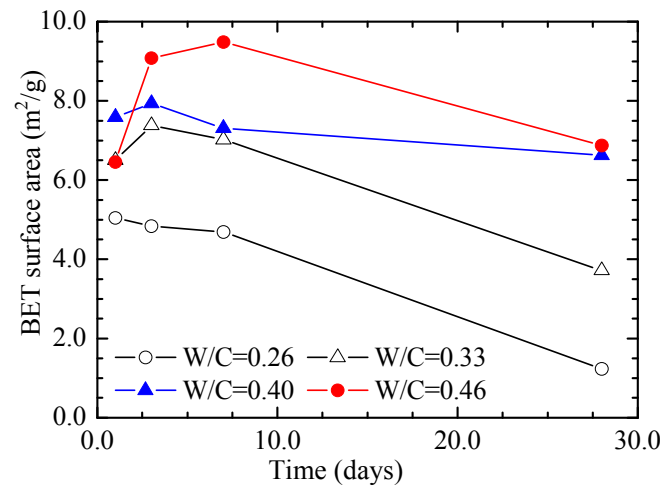

Figure 9. BET surface area of PAC.

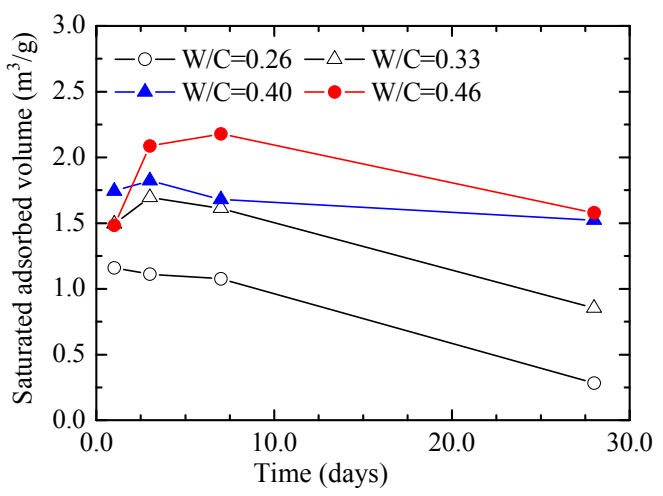

Figure 10. Saturated adsorbed of PAC.

- The porosity of the hardened PAC paste is the continuous pore system from the molecular size to the relatively unlimited pore sizes;

- The amount of nitrogen adsorbed increases as W/C increases and decreases as curing time increases;

- The microstructure of PAC paste is formed at early age due to the cementitious minerals hydrating rapidly. Lots of hydrations fit together to generate distinctive microstructures, the porosity can be reduced and the pore structure will be modified;

- The porosity of the hardened PAC paste primarily comprises the slit-shaped and panel-shaped pores. This is beneficial for the improvement of the antiproliferation properties of the material. The amount of nitrogen adsorbed onto the hardened paste and the surface area enclosed by hysteresis loops decrease as curing time increases;

- The effect of the curing time and the $\mathrm{W} / \mathrm{C}$ value of the hardened PAC pastes on the pore structure are significant. For hardened PAC paste samples, BET surface area and the adsorption quantity both decrease as curing age increases and both increase as $\mathrm{W} / \mathrm{C}$ increases.

\section{Acknowledgements}

This work was supported by National Natural Science
Foundation of China (51078236) and the National Science Fund of China (50925829) for Distinguished Young Scholars.

\section{REFERENCES}

[1] U. Rattanasak and K. Kendall, "Pore Structure of Cement/Pozzolan Composites by X-Ray Microtomogramphy," Cement Concrete Research, Vol. 35, No. 4, 2005, pp. 637-640. doi:10.1016/j.cemconres.2004.04.022

[2] O. Deo and N. Neithalath, "Compressive Behavior of Pervious Concretes and a Quantification of the Influence of Random Pore Structure Features," Materials Science and Engineering: A, Vol. 528, No. 1, 2010, pp. 402-412. doi:10.1016/i.msea.2010.09.024

[3] M. S. Sumanasooriya and N. Neithalath, "Pore Structure Features of Pervious Concretes Proportioned for Desired Porosities and Their Performance Prediction," Cement Concrete Composites, Vol. 33, No. 8, 2011, pp. 778-787. doi:10.1016/j.cemconcomp.2011.06.002

[4] R. Kumar and B. Bhattacharjee, "Porosity, Pore Size Distribution and in Situ Strength of Concrete," Cement Concrete Research, Vol. 33, No. 1, 2003, pp. 155-164. doi:10.1016/S0008-8846(02)00942-0

[5] W. L. Lai and W. F. Tsang, "Characterization of Pore Systems of Air/Water-Cured Concrete Using Ground Penetrating Radar (GPR) through Continuous Water Injection," Construction and Building Materials, Vol. 22, No. 3, 2008, pp. 250-256.

doi:10.1016/j.conbuildmat.2006.08.021

[6] A. K. Ladavos, A. P. Katsoulidis, A. Iosifidis, K. S. Triantafyllidis, T. J. Pinnavaia and P. J. Pomonis, "The BET Equation, the Inflection Points of $\mathrm{N}_{2}$ Adsorption Isotherms and the Estimation of Specific Surface Area of Porous Solids," Microporous and Mesoporous Materials, Vol. 119, No. 4, 2011, pp. 1-8. doi:10.1016/j.micromeso.2011.11.005

[7] H. W. Song and S. J. Kwon, "Permeability Characteristics of Carbonated Concrete Considering Capillary Pore Structure," Cement Concrete Research, Vol. 37, No. 6, 2007, pp. 909-915. doi:10.1016/j.cemconres.2007.03.011

[8] J. J. Thomas, J. Hsieh and H. M. Jennings, "Effect of Carbonation on the Nitrogen BET Surface Area of Hardened Portland Cement Paste," Advanced Cement Based Materials, Vol. 3, No. 2, 1996, pp. 76-80. doi:10.1016/1065-7355(95)00057-7

[9] J. Zhou, Y. E. Guang and K. V. Breugel, "Characterization of Pore Structure in Cement Based Materials Using Pressurization Depressurization Cycling Mercury Intrusion Porosimetry (PDC-MIP)," Cement Concrete Research, Vol. 40, No. 7, 2010, pp. 1120-1128. doi:10.1016/j.cemconres.2010.02.011

[10] J. Kaufmann, R. Loser and A. Leemann, "Analysis of Cement-Bonded Materials by Multi-Cycle Mercury Intrusion and Nitrogen Sorption," Journal of Colloid and Interface Science, Vol. 336, No. 2, 2009, pp. 730-737. doi:10.1016/j.jcis.2009.05.029

[11] B. B. Das and B. Kondraivendhan, "Implication of Pore 
Size Distribution Parameters on Compressive Strength, Permeability and Hydraulic Diffusivity of Concrete," Construction and Building Materials, Vol. 28, No. 1, 2011, pp. 382-386. doi:10.1016/i.conbuildmat.2011.08.055

[12] M. C. G. Juenger and H. M. Jennings, "The Use of Nitrogen Adsorption to Assess the Microstructure of Cement Paste," Cement Concrete Research, Vol. 31, No. 6, 2001, pp. 883-892. doi:10.1016/ S0008-8846(01)00493-8

[13] M. Siegwart, J. F. Lyness and B. J. McFarland, "Change of Pore Size in Concrete Due to Electrochemical Chloride Extraction and Possible Implications for the Migration of Ions," Cement Concrete Research, Vol. 33, No. 8, 2003, pp. 1211-1221. doi:10.1016/S0008-8846(03)00047-4

[14] N. Neithalath, M. S. Sumanasooriya and O. Deo, "Characterizing Pore Volume, Sizes, and Connectivity in Pervious Concretes for Permeability Prediction," Materials Characterization, Vol. 61, No. 8, 2010, pp. 802-813. doi:10.1016/j.matchar.2010.05.004

[15] S. Q. Li, J. S. Hu, B. Liu, G. H. Zhang, W. Cao, Q. Wang, et al., "Fundamental Study on Aluminophosphate Cement," Cement Concrete Research, Vol. 29, No. 10, 1999, pp. 1549-1554. doi:10.1016/S0008-8846(99)00111-8

[16] S. J. Gregg and K. S. W. Sing, "Adsorption Surface Area and Porosity," Academic Press, London, 1967.

[17] A. C. Mitropoulos, "The Kelvin Equation," Journal of Colloid and Interface Science, Vol. 317, No. 2, 2008, pp. 643-648. doi:10.1016/j.jcis.2007.10.001

[18] S. Q. Li, B. Liu, J. P. Cheng and J. S. Hu, "Composite Cement of Magnesium Bearing Phosphoaluminate Hydroxyapatite Reinforced by Treated Raw Silk Fiber," Cement Concrete Composite, Vol. 30, No. 1, 2008, pp. 347-352. doi:10.1016/j.cemconcomp.2007.08.009

[19] L. Z. Xiao and Z. J. Li, "Early Age Hydration of Fresh Concrete Monitored by Non-Contact Electrical Resistivity Measurement," Cement Concrete Research, Vol. 38, No. 3, 2008, pp. 312-319. doi:10.1016/j.cemconres.2007.09.027 